\title{
Zooplankton population dynamics: measuring in situ growth and mortality rates using an Optical Plankton Counter
}

\author{
Are Edvardsen ${ }^{1, *}$, Meng Zhou ${ }^{2, * *}$, Kurt S. Tande ${ }^{1}$, Yiwu Zhu ${ }^{2, * *}$ \\ ${ }^{1}$ Department of Marine and Freshwater Biology, Norwegian College of Fishery Science, University of Tromsø, \\ 9037 Tromsø, Norway \\ ${ }^{2}$ Large Lakes Observatory, University of Minnesota, Duluth, Minnesota 55812, USA
}

\begin{abstract}
An application to assess in situ population dynamics rates is introduced based on the measurements of size-structured zooplankton population. This method differs from those based on species and stages by taking advantage of allometrically-scaled rates, automated sampling devices and net tows. For the first test of this method, we conducted 3 surveys in a nearly enclosed sub-Arctic fjord in northern Norway, from early May to mid June 1998, the period of the spring bloom. Biovolume spectra in the size range between $10^{-1}$ and $10^{3} \mathrm{~mm}^{3}$ individual body volume, from small mesozooplankton to euphausiids, were derived from the Optical Plankton Counter measurements. From 3 bio-volume spectra measured on Days 1, 21, and 35, we calculated in situ individual growth and mortality rates using the theory based on biomass spectra. The net samples corroborate the basic fact that Calanus finmarchicus and euphausiids absolutely dominate in 2 different size ranges. In this spring bloom period, the first generation of Calanus finmarchicus at copepodite stage CIV dominated the size range between 0.3 and $0.58 \mathrm{~mm}^{3}$, and had a growth rate within 0.02 and $0.17 \mathrm{~d}^{-1}$. C. finmarchicus at copepodite stage CV and euphausiid larva dominated the size range from 0.58 to $4 \mathrm{~mm}^{3}$. Their growth rates increased from $0.2 \mathrm{~d}^{-1}$ at the size of $0.71 \mathrm{~mm}^{3}$ to the peak of $0.59 \mathrm{~d}^{-1}$ at the size of $1.9 \mathrm{~mm}^{3}$, and then decreased to $0.22 \mathrm{~d}^{-1}$ at the size of $4 \mathrm{~mm}^{3}$. In the size range above $4 \mathrm{~mm}^{3}$, euphausiid juveniles and adults were absolutely dominant. The growth rate estimated from the biovolume spectra varied between 0.11 and $0.19 \mathrm{~d}^{-1}$ at the size range from 4 to $400 \mathrm{~mm}^{3}$. In the size range between 0.3 and $0.58 \mathrm{~mm}^{3}$, the mortality rate varied between -0.03 and $-0.05 \mathrm{~d}^{-1}$. The mortality rate reached $-0.38 \mathrm{~d}^{-1}$ in the range from 0.71 to $10 \mathrm{~mm}^{3}$. In the size range between 10 and $40 \mathrm{~mm}^{3}$ the rate decreased from -0.31 to $-0.11 \mathrm{~d}^{-1}$, and in the size range above $40 \mathrm{~mm}^{3}$ the rate increased to $-0.27 \mathrm{~d}^{-1}$. The comparison with estimates from net tow samples and literature data indicates that the biomass spectrum theory affords a valuable method for estimating in situ individual growth and population mortality rates by providing high resolution in size classes and a greater degree in accuracy. It is also less labor-intensive and time-consuming than other methods. A test of this method in an advective environment needs further study.
\end{abstract}

KEY WORDS: Population dynamics $\cdot$ Optical Plankton Counter · Individual growth rate $\cdot$ Mortality rate $\cdot$ Zooplankton $\cdot$ Biomass spectrum

\section{INTRODUCTION}

*E-mail: edvard@nfh.uit.no

** Present address: Department of Environmental, Coastal and Ocean Sciences, University of Massachusetts Boston, Massachusetts 02125, USA
Rates of growth and mortality are key processes in population dynamics that, together with behavior and advection, determine the spatial and temporal distributions of zooplankton in oceans. While several valuable 
methods for measuring in situ zooplankton growth rates have been developed (Huntley 1996), none have been easy to assess simply because of difficulties in controlling the quality of net tow samples and sorting species and stages. Studies of in situ mortality are scarce, and methods are difficult to apply (Kimmer \& McKinnnon 1987, Kiørboe et al. 1988, Tande 1988, Carlotti \& Nival 1992b, Aksnes \& Ohman 1996, Ohman et al. 1996a).

One of the errors in net-sample based methods is the inconsistency between the sampling time and the time scales involved in ecosystems. Quantification of zooplankton population dynamics processes on mesoscales is especially challenging because the time needed for net tow sampling is usually longer than the time scale determined by the advection. This time scale mismatch favors the use of rapid sampling methods, such as underway or towed automated acoustic and optical instruments. Most of these instruments provide only the measurements of biomass and size-structured abundance, and do not meet the requirements needed for applying species-stage-based population dynamics models (Aksnes \& Magnesen 1988, Miller \& Nielsen 1988, Carlotti \& Nival 1992a, Huntley et al. 1994, Ohman et al. 1996a).

Another error of species-stage-based models comes from the presumption of constant stage-specific rates of growth and mortality (Omori \& Ikeda 1984). These models require a population to be defined in terms of developmental stages and constant development rates between stages. Problems with this approach include the fact that the individual growth rate is strongly weight-dependent (e.g. Huntley \& Boyd 1984, Brune \& Anderson 1989, Carlotti \& Nival 1991).

We are exploring a new approach based on a sizestructured model and towed automated instruments. This model is grounded in concepts established more than 20 yr ago (Sheldon \& Parsons 1967, Sheldon et al. 1972, 1977, Platt \& Denman 1977, 1978), but has been extended in 2 important ways. First, the model's mathematical equation has been developed as an exact general equation based on the traditional terminology of biomass, individual and population growth rates, and the law of mass conservation. This permits linkage between field measurements, variables in equations, rich literature and traditional interpretation. Second, the theory has been tailored to accept the sizestructured zooplankton data from an Optical Plankton Counter (OPC; Focal Technologies Inc., Dartmouth, Nova Scotia), making it easy to apply to studies of in situ individual weight-specific growth rates and population growth rates.

The first test of this approach was applied to assess dynamic rates of zooplankton in a Norwegian high latitude fjord. Choosing a high latitude fjord allows us to have well-defined cohorts separated in time during the productive season, and avoids the advective effect that is different from population dynamics processes of growth and mortality. We address only the essential questions: What kinds of measurements are needed? and, How do we inversely calculate population dynamics rates based on the size-structured model?

\section{THEORIES}

The biomass spectrum was first described by Sheldon \& Parsons (1967), wherein organisms in an assemblage are uniquely classified according to weight (regardless of species) known simply as the size-structured population. Based on their approach, the classical population concept is not central, but in our context the model can address rates pertinent to 1 population of a single species, or to several populations covering a suite of coexisting species. Thus, the size-structured population approach does not discriminate between different species and stages, but the concept operates in concert with the principles in classical population dynamics, where population growth rate is a result of births and deaths within the time window studied. The so-called normalized biomass spectrum, $b(w)$, is defined as

$$
b(w)=\text { biomass within } \Delta w / \Delta W\left(\mathrm{~m}^{-3}\right)
$$

where $w$ is the body weight, and $\Delta w$ is the weight interval. From the mass conservation, Zhou \& Huntley (1997) further developed a general equation describing the relation between the temporal change of the biomass spectrum and rates of individual growth and population growth, i.e.

$$
\frac{\partial b}{\partial t}+\frac{\partial(w g b)}{\partial w}=g b+\mu b
$$

where $g$ is the mean specific individual growth rate and $\mu$ is the mean specific population growth rate in weight class $w$. Eq. (2) is an exact representation of the zooplankton biomass conservation and biomass fluxes from small to large size classes.

With appropriate data, Eq. (2) can be used inversely to estimate in situ $g$ and $\mu$. These data would be in the form of a time series of measurements of $b\left(w_{j}, t_{i}\right)$ at $\left(w_{j}=\right.$ $\left.w_{1}, w_{2}, \ldots, w_{J}\right)$ and $\left(t_{i}=t_{1}, t_{2}, \ldots, t_{N}\right)$, where $\left(w_{1}, w_{2}, \ldots, w_{J}\right)$ are the zooplankton weight (size) classes. To demonstrate, we assume we have these measurements at $\left(t_{1}\right.$, $\left.t_{2}, t_{3}\right)$. Using the finite difference to replace the differential in Eq. (2), and note $b_{j, n}=b\left(w_{j}, t_{n}\right)$, we can have

$$
\frac{b_{n-1}-b_{j, n}}{t_{n+1}-t_{n}}+\frac{w_{j} g_{j} b_{j, n}-w_{j-m} g_{j-m} b_{j-m, n}}{w_{i}-w_{i-m}}=g_{j} b_{j, n}+\mu_{j} b_{j}
$$

at $j=m+1, \ldots J$, and $n=1,2$. The index of $m$ needs to be determined. Unknowns are $g_{1}, g_{2}, \ldots, g_{J_{t}} \mu_{1}, \mu_{2}, \ldots, \mu_{J_{t}}$ the individual and population growth rates in each weight class. 
The numerical method used in Eqs. (3) and (4) is the finite difference, upwind scheme (Marchuk 1975). To obtain a so-called convergent solution and to avoid accumulative computational errors, the CourentFriedrich-Lewy (CFL) stability condition must be met. In a general first order wave equation, the condition can be written as

$$
\frac{\Delta x}{\Delta t} \geq v
$$

where $\Delta x$ is the spatial grid size, $\Delta t$ is the time step, and $v$ is the phase speed of a wave. We cannot directly apply this condition to Eq. (3) because $\Delta w$ is not constant during our data process. We choose the size interval on the logarithms coordinate of $w, \Delta \ln (w)$, to be constant (discussed in a later section). To obtain the stability condition, we need to rearrange Eq. (2) after expanding the second term on the left side, i.e.

$$
\frac{\partial b}{\partial t}+w g \frac{\partial b}{\partial w}+w b \frac{\partial g}{\partial w}=\mu b
$$

Multiplying $(1 / b)$ to both sides and rearranging, we obtain

$$
\frac{\partial \ln (b)}{\partial t}+g \frac{\partial \ln (b)}{\partial \ln (w)}=\mu-\frac{\partial(g)}{\partial \ln (w)}
$$

Taking the difference of Eq. (6), the terms on the right side are nonhomogeneous terms and do not affect the stability. The variables of $\ln (w)$ and $g$ correspond to $x$ and $v$ in the CFL condition 4 . Thus, the CFL condition for the difference equation of Eq. (6) is

$$
\frac{\hat{\Delta} \ln (w)}{\hat{\Delta} t} \geq g
$$

where $\hat{\Delta} \ln (w)$ is the difference between any 2 size classes (which is different from the interval between 2 neighboring size classes). Taking the size classes determined during data processing as $\left[\ln \left(w_{1}\right), \ln \left(w_{2}\right)\right.$, $\left.\ldots, \ln \left(w_{J}\right)\right]$, the CFL condition 7 for class $j$ can be rewritten as

$$
\frac{\ln \left(w_{j}\right)-\ln \left(w_{j-m}\right)}{\Delta t} \geq g_{j}
$$

This condition indicates that if the $\Delta t$ is predetermined by the interval of surveys, $m$ can be determined by $\ln \left(w_{m}\right) \approx \ln \left(w_{1}\right)+g_{m} \Delta t$. At $j=m+1$ and $j-m=1$, we obtain the lower limit of the size class for estimating $g$ and $\mu$. Because Eqs. (2) and (6) are equal, the CFL condition 8 can be applied to Eq. (3).

From Eq. (3), we can have $2 \times(J-m)$ unknowns, i.e. $g_{m+1}, g_{m+2}, \ldots, g_{J}, \mu_{m+1}, \mu_{m+2}, \ldots, \mu_{J}$ and from the measurements at $t_{1}, t_{2}, t_{3}$ and Eq. (3), we can have only $2 \times$ $(J-m-1)$ equations. The system formed by this group of equations is weakly underdetermined. If we have measurements at $t_{1}, t_{2}, t_{3}, t_{4}$, we will have $3 \times(J-m-1)$ equations, which form an over-determined system. An easy way to solve such an under- or over-determined system is the least-squares method. The error of Eq. (3), $\varepsilon_{j, n}$, can be written as

$\varepsilon_{j, n}=\frac{b_{j, n+1}-b_{j, n}}{t_{n+1}-t_{n}}+\frac{w_{j} g_{j} b_{j, n}-w_{j-m} g_{j-m} b_{j-m, n}}{w_{j}-w_{j-m}}-g_{j} b_{j, n}-\mu_{j} b_{j}$

The least-squares error is defined as the sum of squares of $\varepsilon_{j, n}$, i.e.

$\varepsilon^{2}=\sum_{n-1}^{N-1} \sum_{J=m+1}^{J}\left(\frac{b_{j, n+1}-b_{j, n}}{t_{n+1}-t_{n}}+\frac{w_{j} g_{j} b_{j, n}-w_{j-m} g_{j-m} b_{j-m, n}}{w_{j}-w_{j-m}}-g_{j} b_{j, n}-\mu_{j} b_{j,} n\right)^{2}$

By minimizing $\varepsilon^{2}$, we can solve $g_{j}$ and $\mu_{j}$, i.e.

$$
\frac{\partial \varepsilon^{2}}{\partial g_{j}}=0, \text { and } \frac{\partial \varepsilon^{2}}{\partial \mu_{j}}=0 \quad(j=m+1, \ldots, J)
$$

Eq. (11) leads to $2 \times(J-m)$ linear equations for $2 \times$ $(J-m)$ unknowns. This group of linear equations can be solved by the Gaussian elimination (Stoer \& Bulirsch 1980)

Eqs. (3), (8) and (11) should be the principles guiding the fieldwork. First, we need at least 3 surveys that will form a weakly-underdetermined system. Second, the rates at a portion of small size range $\left(w_{1}, w_{1}+g_{m} \Delta t\right)$ cannot be solved due to a finite time interval between 2 surveys; by reducing this time interval we can reduce this portion. The rates can then be solved from Eq. (11).

\section{SURVEYS AND DATA}

\section{Study site and surveys}

We chose Sørfjorden in northern Norway as our study site because of its relatively simple physical and biological settings. This fjord is a branch of Ullsfjorden, which is linked to the coastal ocean by a $150 \mathrm{~m}$ deep channel. Sørfjorden is $25 \mathrm{~km}$ long and 2 to $4 \mathrm{~km}$ wide. Its topography features 2 deep basins, approximately $120 \mathrm{~m}$ deep, separated by shallows of $50 \mathrm{~m}$. Sørfjorden is nearly enclosed from Ullsfjorden by a $400 \mathrm{~m}$ wide sill with a mean depth of only $8 \mathrm{~m}$. The taxonomy of zooplankton in Sørfjorden is dominated by only 2 species, Calanus finmarchicus and euphausiids. These special physical and biological settings allow us to more effectively elucidate the inverse methods for calculating the population dynamics rates outlined by Eqs. (3), (8) and (11) without dealing with any advection effect and the composition of species.

The peak tidal current is approximately $1 \mathrm{~m} \mathrm{~s}^{-1}$ at the narrow and shallow entrance of Sørfjorden. In the fjord, the tidal current does not exceed $0.1 \mathrm{~m} \mathrm{~s}^{-1}$, and the tidal excursion is approximately $300 \mathrm{~m}$ during a tidal period. The baroclinic current, which plays the 
primary role for the 2-way exchange at the entrance, usually does not exceed $0.1 \mathrm{~m} \mathrm{~s}^{-1}$. The residence time $\left(T_{\text {res }}\right)$ can be estimated by:

$T_{\text {res }}=$

Volume of Sørfjord / Volume flux at the entrance

The volume of Sørfjorden and the volume flux through the entrance are approximately $3.1 \times 10^{9} \mathrm{~m}^{3}$ and $160 \mathrm{~m}^{3} \mathrm{~s}^{-1}$, respectively. Hence, the residence time of water is approximately $200 \mathrm{~d}$, which justifies considering Sørfjorden as a nearly enclosed fjord.

Most of the year, the zooplankton community in northern Norwegian fjords is dominated by copepods up to approximately $95 \%$ in biomass (Falkenhaug et al. 1997). Of the copepods, Calanus finmarchicus accounts for $90 \%$ of the abundance in the mesozooplankton size range in late spring and summer. During June, C. finmarchicus develops through the late copepodite stages (CIII to $\mathrm{CV}$ ), which exhibit the largest stage-specific weight increments and maximum growth rates (Tande 1991, Tande \& Slagstad 1992, Aksnes \& Blindheim 1996). In the size range larger than copepods, the 3 Thysanoessa species (Thysanoessa inermis, T. rachii and $T$. longicaudata) are the dominant euphausiids accounting for more than $90 \%$ of biomass (Falk-Petersen et al. 1981, Hopkins et al. 1984, FalkPetersen 1985). All these species grow rapidly in spring and summer, while their growth during winter is interrupted by a lack of food. Thus, we have a very simple community dominated by $C$. finmarchicus and euphausiids in 3 different size ranges: juveniles (calyptopes and furcilia) and 2 cohorts with an age of 1 and 2 yr, respectively.

We took 3 short-term cruises onboard RV 'Johan Ruud' from May 11 to 15, June 2 to 5, and June 15 to 19, in 1998, during which we expected to find the maximum growth for both copepods and euphausiids in that area. The maximum interval between 2 biomass spectra is $21 \mathrm{~d}$. Taking the residence time of $200 \mathrm{~d}$ estimated above, the relative error in measurements produced by advection should not exceed $10 \%$.

\section{Sampling methods}

The OPC was mounted on a towed MKII Scanfish (GMI, Kvistgaard, Denmark). Technical details of the OPC can be found in Herman (1988 and 1992), and Herman et al. (1993). Briefly, the optical sensors situated on each side of the flow tunnel count the number and measure the equivalent spherical diameter (ESD) of particles in 3431 digital sizes within a range from 0.25 to $14 \mathrm{~mm}$. Underneath the slit of the tunnel, a Hydrobios mechanical flow meter measures the flow of water. The digital data of measurements of plankton and flow are transmitted via the conducting wires in the towing cable to a computer onboard the ship. The OPC data are integrated with conductivity-temperature-depth (CTD) sensor measurements and Global Positioning System (GPS) data by the data acquisition software and stored on the hard-drive.

The integrated Scanfish package undulates within the pre-programmed path during towing. In this study the undulation range was typically from $3 \mathrm{~m}$ below surface to $10 \mathrm{~m}$ above the bottom, or at a maximum depth of $100 \mathrm{~m}$. The maximum time of a whole undulation (from surface to surface) was $<5 \mathrm{~min}$, which is equivalent to a travel distance of approximately $800 \mathrm{~m}$ at a ship speed of 6 knots. All measurements and sampling were conducted on a standard cruise track along the principal axis of Sørfjorden (see Fig. 1).

In addition, at 15 stations along the Scanfish-OPC transects we conducted regular vertical sampling of temperature, salinity and fluorescence by using a Multipar-CTD (ME Meerestechnik-Eletronik GmbH, Trappenkamp, Germany) and a BackScat Fluorometer (Model 1121 MP/Chla; Dr. Haardt, Klein-Barkau, Germany). At 3 sites near the centers of 3 basins (Fig. 1) we obtained zooplankton samples by using a multiple opening and closing nets and environmental sampling system (MOCNESS; Wiebe et al. 1985). The net mesh size is $180 \mu \mathrm{m}$. Each net tow sample was concentrated and preserved in $4 \%$ formaldehyde in seawater buffered with hexamine. A bactericide, 1,5-propane-diol ( $5 \%$ by volume), was added to the preservative. All specimens in aliquots of approximately 1000 animals were counted and identified under a Wild M3 stereomicroscope at 6 to $50 \times$ magnification.

The relation between the OPC ESD sizes and the volumes of stages CI to CV and adult females of Calanus finmarchicus was obtained by utilizing the computer image analysis software (Scion Image, Scion Corp., Frederick, MD, USA). During the analysis, we used approximately 100 specimens of stages from CI to $\mathrm{CV}$ and adult females of $C$. finmarchicus. The image of a specimen was taken under a microscope equipped with a digital camera. The stage-specific volume was estimated based on image analysis of both dorsal and lateral view. We used at least 20 individuals per stage. Length and area measurements were used to calculate the volume of the prosome and appendages.

\section{Data processing}

\section{OPC data processing}

OPC data were processed based on the bio-volume of each count, which can be directly calculated from its ESD. Ideally, had we known the relation between 


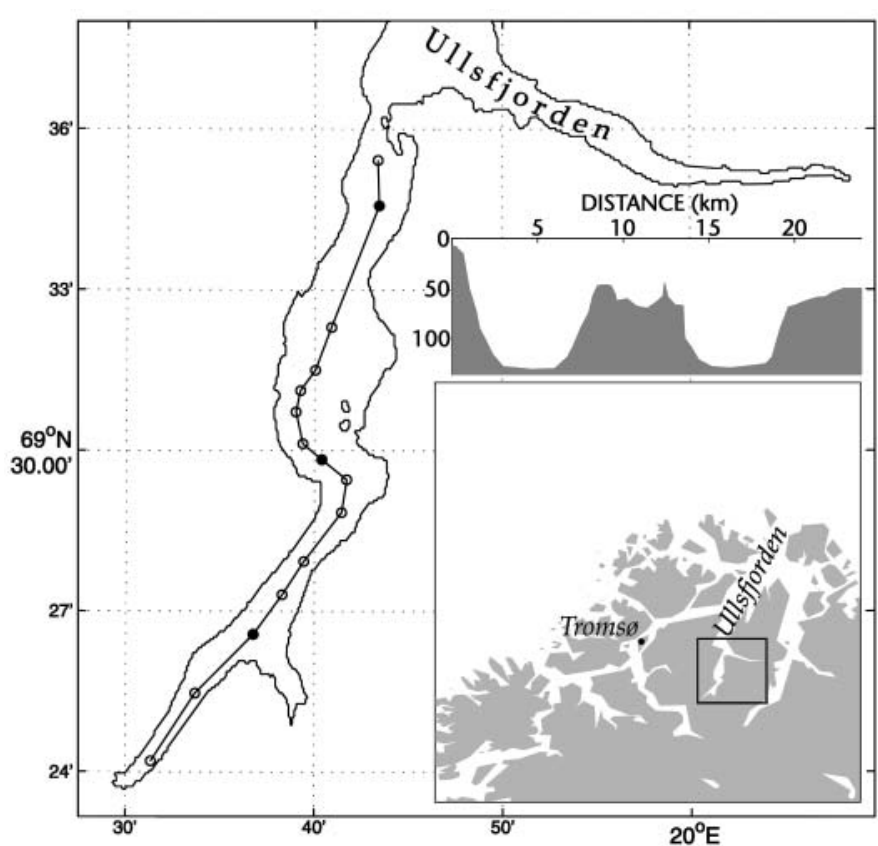

Fig. 1. The geographic location of Sørfjorden in northern Norway, and its bottom topography. The solid line indicates the OPC transect; (०): CTD stations; and (•): MOCNESS stations

plankton body volume and body carbon, biomass spectra could have been calculated from the OPC measurements. Due to the lack of historic data and funds for additional measurements, we had to choose the biovolume spectrum instead of biomass spectra. The definition of the bio-volume spectrum, consistent with the definition of the biomass spectrum in Eq. (1), is:

$$
B_{V}\left(W_{V}\right)=\text { bio-volume within } \Delta W_{V} / \Delta W_{V}\left(\mathrm{~m}^{-3}\right)
$$

where $w_{V}$ is the bio-volume of an individual, and $B_{V}$ is the bio-volume spectrum. If we assume that the ratio of body carbon to body volume $\left(\rho_{v}\right)$ remains constant, we have $w=\rho_{V} w_{V}$ and $B=\rho_{V} B_{V}$. Thus, Eqs. (2), (3), (8) and (11) are still valid after replacing $W$ and $B$ with $W_{V}$ and $B_{V}$, respectively.

The volume measurements by the Hydrobios mechanical flowmeter on the OPC is calibrated in order to obtain the estimates of absolute abundance and biovolume spectra by a unit volume. To avoid any error

Table 1. Comparison of flow measurements from the OPC flow meter and flow calculated from position and depth readings

\begin{tabular}{|lcccc|}
\hline & $\begin{array}{c}\text { Number of } \\
\text { measurements }\end{array}$ & $\begin{array}{c}\text { Mean } \\
\left(\mathrm{m} \mathrm{s}^{-1}\right)\end{array}$ & $\begin{array}{c}\text { STD deviation } \\
\left(\mathrm{m} \mathrm{s}^{-1}\right)\end{array}$ & $\begin{array}{c}\text { Error at 95\% } \\
\text { confidence }\left(\mathrm{m} \mathrm{s}^{-1}\right)\end{array}$ \\
\hline Hydrobios & & & & \\
Flow meter & 2900 & 2.656 & 0.363 & 0.013 \\
Estimates by GPS & 2900 & 2.613 & 0.279 & 0.010 \\
\hline
\end{tabular}

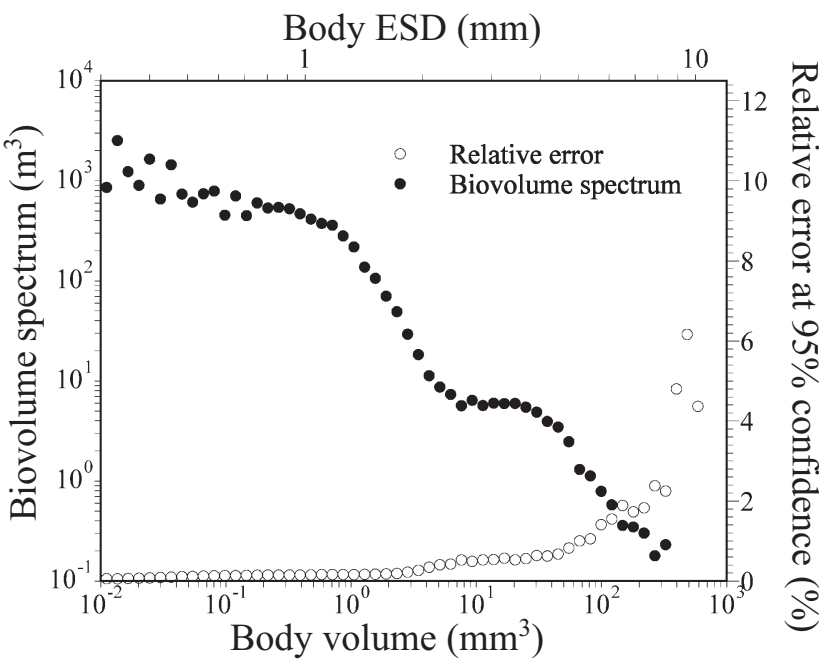

Fig. 2. A typical OPC biomass spectrum and its relative error at $95 \%$ confidence level

introduced by the current, half of the flow measurements were taken when the ship steamed upstream, and the other half when the ship steamed downstream during the calibration. At each flow measurement, we made an independent estimate of the flow rate by using 2 GPS fixes, 2 depth measurements, and the duration between these 2 fixes. The statistical results are shown in Table 1. The mean flow speed measured by the flow meter is nearly similar to the mean estimate of flow obtained by the GPS and depth fixes.

We also regrouped the OPC original 3431 digital sizes into 60 sizes with an equal interval on the $\log _{10}$ (body volume). At the typical towing speed of 6 knots, the flux of water through the aperture of $0.005 \mathrm{~m}^{2}$ is approximately equal to $0.015 \mathrm{~m}^{3} \mathrm{~s}^{-1}$. Taking the mean abundance of plankton of 5000 individuals $\mathrm{m}^{-3}$, the average number of plankton counted between 2 time marks $(0.5 \mathrm{~s})$ is approximately 38 individuals. This does not represent a statistically meaningful spectrum of 3431 sizes. To reduce this under-sampling problem, we first integrated the measurements in vertical $10 \mathrm{~m}$ bins, and regrouped 3431 digital sizes into 60 sizes with an equal interval on the $\log _{10}$ (body volume). The typical values of the water volume filtered and the number of plankton counted by the OPC for 1 independent measurement of a 60 size spectrum are $0.2 \mathrm{~m}^{3}$ and 1000 individuals, respectively. A typical tow consisted of 2 upstream and downstream transects, each of which covered the entire fjord along the principle axis. Approximately 1050 independent measurements of bio-volume spectra were taken. Fig. 2 shows the mean bio-volume spectrum, standard deviation and its relative error at $95 \%$ confidence level. 
Calculation of population dynamics rates based on bio-volume spectra

It is not trivial to determine the lowest size class $w_{m}$. The maximum interval between 2 spectra is equal to $21 \mathrm{~d}$, which determines the lowest size class $w_{m}$ in our calculations. Without knowing the maximum growth rate of small zooplankton for estimating the lowest size class prior to our calculations, the value of $w_{m}$ can be determined through a series of trials. First, we chose the maximum specific growth rate of $0.05 \mathrm{~d}^{-1}$ at the temperature of $3^{\circ} \mathrm{C}$ based on Huntley \& Lopez (1992). The value of $w_{m}$ can be estimated by Eq. (8). In our calculation, the solution was apparently non-convergent because the resultant maximum growth rate was significantly larger than the assumed rate of $0.05 \mathrm{~d}^{-1}$. After a series of trials, we chose $w_{m} \approx 0.14 \mathrm{~mm}^{3}$, which corresponds to Class 14, the ESD of approximately $0.64 \mathrm{~mm}$, and the mean growth rate of approximately $0.1 \mathrm{~d}^{-1}$.

The difference equations given by Eqs. (8) and (11) gave 94 linear equations for 94 unknowns of $g_{i}$ and $\mu_{i}$ from Class 14 to 60 for every 2 pairs of bio-volume spectra from the 3 surveys. This group of linear equations was then solved numerically by the Gaussian elimination (Stoer \& Bulirsch 1980). From all biovolume spectra of tows in 3 surveys, we obtained 16 different estimates of $g_{i}$ and $\mu_{i}$ for 47 size classes. The mean estimates of $g_{i}$ and $\mu_{i}$ are defined as the ensemble averages, i.e.

$$
\begin{aligned}
& \bar{g}_{j}=\left\langle g_{j}\right\rangle \\
& \bar{\mu}_{j}=\left\langle\mu_{j}\right\rangle
\end{aligned}
$$

where the angle brackets are the ensemble averages. Their errors at the $95 \%$ confidence level are:

$$
\begin{aligned}
& \varepsilon_{g_{j}}=\frac{1.96 \sigma_{g_{j}}}{\sqrt{N}} \\
& \varepsilon_{\mu_{j}}=\frac{1.96 \sigma_{\mu_{j}}}{\sqrt{N}}
\end{aligned}
$$

where $\sigma_{g_{j}}$ and $\sigma_{\mu_{j}}$ are the standard deviations. The estimated means and errors are shown in Fig. 6.

\section{Calculation of population dynamics rates based on net tow sample data}

We can learn some information on the population dynamics process from net tow sample data under some restricted conditions. Using the definition of individual growth rate, i.e.

$$
g=\frac{1}{w} \frac{\mathrm{d} w}{\mathrm{~d} t}
$$

the growth rate from weight measurements can be estimated by:

$$
g=\frac{1}{T} \ln \left(\frac{w(t+T)}{w(t)}\right)
$$

Eq. (18) can be simply applied only if we assume that the mean weight of individuals is adequately represented from net tow samples in the period of $T$, which can be biased by selective predation on sizes. The errors of the estimates using Eq. (18) can be made by differentiating Eq. (18) and taking absolute values of all terms, i.e.

$$
\Delta g \leq\left|\frac{g}{T} \Delta T\right|+\left|\frac{1}{T w(t+T)} \Delta w(t+T)\right|+\left|\frac{1}{T w(t)} \Delta w(t)\right|
$$

where $\Delta T$ and $\Delta W$ are the error at the $95 \%$ confidence level, and $\Delta g$ is the error at the $95 \%$ confidence level produced by $\Delta T$ and $\Delta W$. The $95 \%$ confidence interval of $w$ is estimated from our laboratory analysis. The error of $T$ is produced by the time differences of net tows. It is assumed to be $5 \mathrm{~d}$, which corresponds to the duration of each cruise. The estimates of both means and errors are shown in Table 2.

To calculate the mortality, we can follow the same population in 3 cruises, and employ the definition of population growth rate, i.e.

$$
\mu=\frac{1}{N} \frac{\mathrm{d} N}{\mathrm{~d} t}
$$

The population growth rate can be roughly estimated by:

$$
\mu=\frac{1}{N} \ln \left(\frac{N(t+T)}{N(t)}\right)
$$

The error induced by the error of abundance estimates can be analyzed by differentiating Eq. (21), i.e.

$$
\Delta \mu \leq\left|\frac{\mu}{T} \Delta T\right|+\left|\frac{1}{T N(t+T)} \Delta N(t+T)\right|+\left|\frac{1}{T N(t)} \Delta N(t)\right|
$$

where $\Delta N$ is the error of $N$ at the $95 \%$ confidence level, and $\Delta \mu$ is the error at the $95 \%$ confidence level produced by $\Delta T$ and $\Delta N$. The relative error of $\mu$ contributed by $\Delta T$ is similar to the error of $g$, and is equal to $(\Delta T / T)$. The errors in abundance estimates from net tows are difficult to calculate because we do not know the net catch efficiency that forbids us to give the error estimates for the mortality. The means are shown in Table 2.

\section{RESULTS AND DISCUSSION}

\section{General physical and biological environment}

Our temperature and salinity measurements show that during our survey period, the water column was stratified. In the inner part of the fjord the deep water is the coolest and saltiest (Fig. 3). The surface water 
Fig. 3. Representative profiles of temperature, salinity, OPC plankton abundance, and fluorescence concentration along the principal axis in Sørfjorden during the first cruise in 1998. Distance is set to 0 at the outlet of Sørfjorden

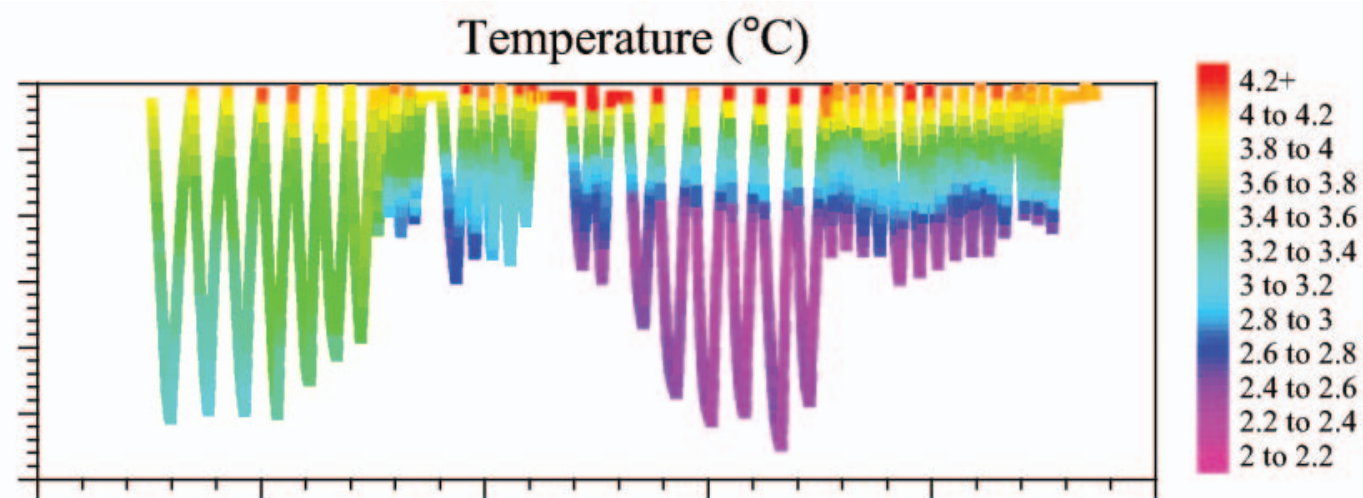

Salinity (\%)

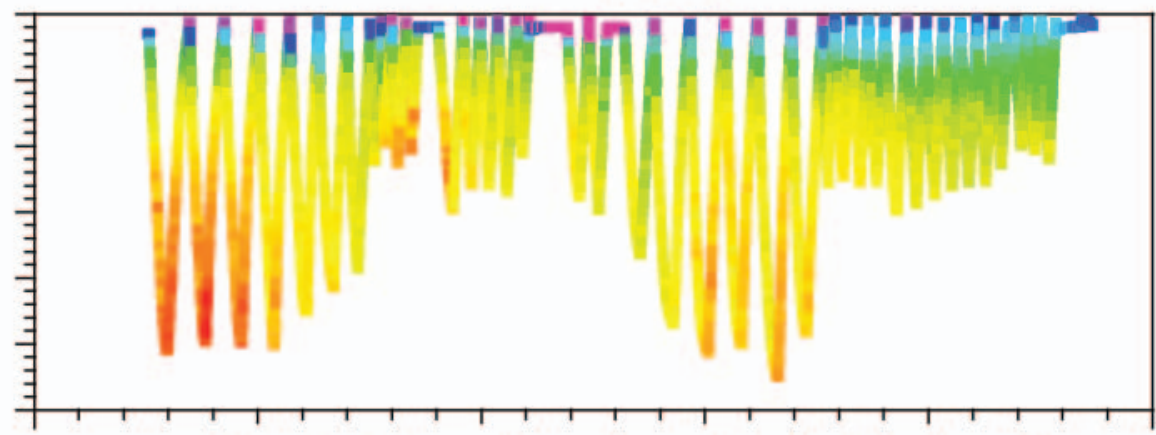

$33.7+$

33.6 to 33.7

33.5 to 33.6

33.4 to 33.5

33.3 to 33.4

33.2 to 33.3

33.0 to 33.2

32.9 to 33.0

32.8 to 32.9

32.7 to 32.8

32.6 to 32.7

32.5 to 32.6

Zooplankton Abundance (individuals $\mathrm{m}^{-3}$ )

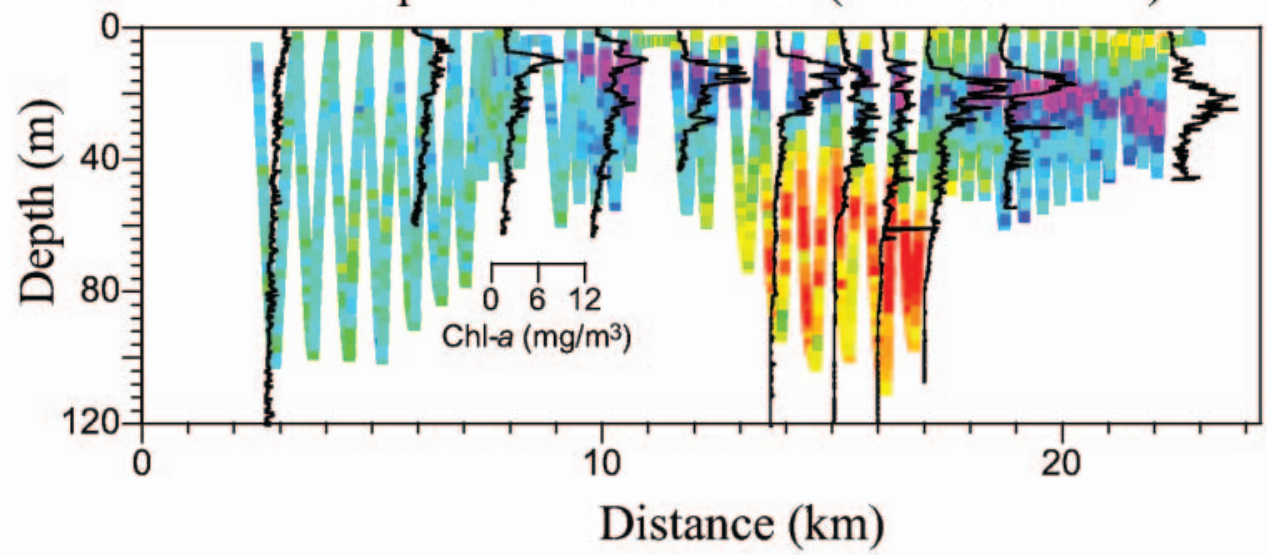

$7000+$

6500 to 7000

6000 to 6500

5500 to 6000

5000 to 5500

4500 to 5000

4000 to 4500

3500 to 4000

3000 to 3500

2500 to 3000

2000 to 2500

1500 to 2000

Table 2. Growth rates estimated from MOCNESS data and body volumes (Table 3). We have reason to believe that the peak of the Calanus finmarchicus population during Cruise I is at the late naupliar phase. Body volume of nauplii was not measured and the body volume of copepodite CI was used for the calculations. This will lead to a slightly underestimated value of calculated growth rate between Cruise I and Cruise II. CI, CIII and CIV: copepodites stages I, III and IV, respectively

\begin{tabular}{|c|c|c|c|c|c|}
\hline \multirow{3}{*}{$\begin{array}{l}\text { Mean time interval (d) } \\
\text { Dominant stage }\end{array}$} & \multirow{3}{*}{$\begin{array}{c}\text { Cruise I } \\
\text { CI }\end{array}$} & \multirow{3}{*}{21} & Cruise II & \multirow{3}{*}{13} & \multirow{3}{*}{$\begin{array}{c}\text { Cruise III } \\
\text { CIV }\end{array}$} \\
\hline & & & & & \\
\hline & & & CIII & & \\
\hline Elipsoid body-volume $\left(\mathrm{mm}^{3}\right)$ & 0.021 & & 0.140 & & 0.346 \\
\hline Growth rates $\left(\mathrm{d}^{-1}\right)$ & & $0.09 \pm 0.04$ & & $0.07 \pm 0.06$ & \\
\hline Perimeter body-volume $\left(\mathrm{mm}^{3}\right)$ & 0.024 & & 0.148 & & 0.393 \\
\hline Growth rates $\left(\mathrm{d}^{-1}\right)$ & & $0.09 \pm 0.04$ & & $0.08 \pm 0.06$ & \\
\hline Cylinder body-volume $\left(\mathrm{mm}^{3}\right)$ & 0.027 & & 0.179 & & 0.470 \\
\hline Growth rates $\left(\mathrm{d}^{-1}\right)$ & & $0.09 \pm 0.05$ & & $0.08 \pm 0.07$ & \\
\hline
\end{tabular}


has the lowest salinity and is relatively warmer than the deep water. This temperature and salinity structure indicates that the deep water in the fjord was overturned by the coolest and saltiest water formed at the surface due to surface cooling and ice formation during winter. In spring, the fresher surface water is formed by runoff of melting snow and ice.

At the time of our first cruise, the water column was already stratified, and the phytoplankton crop (in terms of fluorescence concentration) peaked at approximately $20 \mathrm{~m}$ below the surface (Fig. 3). During the second and the third cruises, the fluorescence concentration decreased and the water column became progressively more stratified. We may therefore conclude that our sampling program took place during post-bloom conditions, the period when Calanus finmarchicus and euphausiids have the most intensive growth (Hopkins et al. 1984, Tande 1991).

\section{The relation between the ESD size and body length of Calanus finmarchicus}

The stage-specific volume estimates were made from length and area measurements. We applied 3 models for the volume of the prosome (including mouth appendages): a cylinder, an ellipsoid and a perimeter model based on cross sectional area and the prosome circumference (Massana et al. 1997). The cylinder has its diameter and height according to the prosome width and length (prosome width $>$ prosome height), the ellipsoid has its major and 2 minor axes from the prosome length, height and width. To estimate volume, the perimeter model assumes that the body is a cylinder with 2 hemispherical caps, i.e.

$$
\begin{aligned}
& W_{e}=\frac{P-\sqrt{P^{2}-4 \pi A}}{\pi} \\
& L_{e}=\frac{P}{2}+W_{e}\left(1-\frac{\pi}{2}\right)
\end{aligned}
$$

$$
V=\frac{\pi}{4} W_{e}^{2}\left(L_{e}-\frac{W_{e}}{3}\right)
$$

where $W_{e}$ and $L_{e}$ are the equivalent width and length, $V$ is the volume, $P$ is the circumference, and $A$ is the cross-sectional area of the lateral projection of the prosome. The volumes of appendages (i.e. antennae, legs and urosome) were calculated from the measured areas of the lateral views multiplied by the mean diameter of the antennae, where we assumed that the diameters of the legs and urosome are approximately equal to that of the antennae. Based on our measurements, the total volume of appendages makes up 10 to $20 \%$ of the prosome volume depending on various models.

Table 3 shows the relation between the length and estimated body volume. The estimates show that there are significant differences between these 3 models. The maximum difference between models varies from $25 \%$ at $\mathrm{CI}$ to $37 \%$ at $\mathrm{Cf}$ (adult female). Due to a lack of information on what the OPC really measures, the minimum and maximum estimates at a given stage from different models give the lower and upper limits of OPC measurements, which will explain how these differences may affect the accuracy of estimates of population dynamics rates.

\section{Comparison between samples from nets and OPC measurements}

The MOCNESS samples indicate that during our cruises the zooplankton community in Sørfjorden was dominated by Calanus finmarchicus. Based on previous studies of northern Norwegian fjords, it was to be expected that $C$. finmarchicus would proceed through its most intensive growth and recruitment during the period of these 3 cruises (Hopkins et al. 1984, Tande \& Slagstad 1992, Falkenhaug et al. 1997). Because Sørfjorden is nearly enclosed, total abundance of C. finmarchicus should gradually decrease due to mortality. The bio-volume spectra obtained by the OPC indicate

Table 3. Stage-specific biometrical data $( \pm \mathrm{SD})$ of Calanus finmarchicus from Sørfjorden. These measurements were applied to

\begin{tabular}{|c|c|c|c|c|c|c|c|}
\hline & Stage & CI & CII & CIII & CIV & $\mathrm{CV}$ & $\mathrm{Cf}$ \\
\hline Prosome (mm) & $\begin{array}{l}\text { length } \\
\text { width } \\
\text { height }\end{array}$ & $\begin{array}{l}0.76 \pm 0.05 \\
0.25 \pm 0.02 \\
0.21 \pm 0.02\end{array}$ & $\begin{array}{l}1.06 \pm 0.04 \\
0.32 \pm 0.02 \\
0.27 \pm 0.02\end{array}$ & $\begin{array}{l}1.53 \pm 0.04 \\
0.45 \pm 0.02 \\
0.38 \pm 0.02\end{array}$ & $\begin{array}{l}2.00 \pm 0.12 \\
0.60 \pm 0.04 \\
0.54 \pm 0.05\end{array}$ & $\begin{array}{l}2.74 \pm 0.12 \\
0.87 \pm 0.05 \\
0.82 \pm 0.07\end{array}$ & $\begin{array}{l}2.61 \pm 0.32 \\
0.84 \pm 0.12 \\
0.80 \pm 0.11\end{array}$ \\
\hline Volume $\left(\mathrm{mm}^{3}\right)$ & $\begin{array}{l}\text { Elipsoid } \\
\text { Perimeter } \\
\text { Cylinder }\end{array}$ & $\begin{array}{l}0.021 \pm 0.004 \\
0.024 \pm 0.005 \\
0.027 \pm 0.006\end{array}$ & $\begin{array}{l}0.048 \pm 0.006 \\
0.054 \pm 0.011 \\
0.063 \pm 0.010\end{array}$ & $\begin{array}{l}0.140 \pm 0.015 \\
0.148 \pm 0.017 \\
0.179 \pm 0.024\end{array}$ & $\begin{array}{l}0.346 \pm 0.069 \\
0.393 \pm 0.077 \\
0.470 \pm 0.110\end{array}$ & $\begin{array}{l}1.045 \pm 0.161 \\
1.200 \pm 0.174 \\
1.505 \pm 0.279\end{array}$ & $\begin{array}{l}0.948 \pm 0.377 \\
1.132 \pm 0.479 \\
1.370 \pm 0.546\end{array}$ \\
\hline $\mathrm{ESD}(\mathrm{mm})$ & & $0.525 \pm 0.027$ & $0.708 \pm 0.033$ & $0.981 \pm 0.036$ & $1.331 \pm 0.073$ & $1.882 \pm 0.073$ & $1.814 \pm 0.231$ \\
\hline
\end{tabular}
the different volume calculations (see text for details). ESD was calculated from the lateral cross sectional area obtained from image analysis. CI to CV: copepodite stages I to V; Cf: adult female 
the decline through time in the bio-volume corresponding to the copepod size window. At a given size, the bio-volume reflects the abundance of zooplankton. Contradictorily, MOCNESS data indicate that the abundance of C. finmarchicus was lower during Cruise 1 than during Cruises 2 and 3. Though our limited data were unable to explain this contradiction, it has been proved that the OPC provides accurate counts in the size range of copepods under different environmental settings (Sprules et al. 1998, WooddWalker et al. 2000, Zhang et al. 2000). The disagreement between OPC counts and net tow samples is often found because of either leakage or avoidance of zooplankton (A. W. Herman unpubl.). We employed a mesh size of $180 \mu \mathrm{m}$. Nichols \& Thompson (1991) found that nauplii and copepodite I of Calanus spp. tend to slip through meshes of 124 and $192 \mu \mathrm{m}$. During the first cruise, our nets were clogged by phytoplankton aggregates even after we reduced our towing time. The bowl wave produced in front of the net might also have reduced the sampling efficiency of the net and possibly increased the avoidance of zooplankton. Thus, our net tow samples cannot give us estimates of absolute abundance. What we can learn is the percentage composition of species and stages, and the relation between sizes, species and stages.

The phytoplankton aggregates and marine snows are of major non-zooplankton contaminants. How the phytoplankton aggregates contaminate the OPC measurements can be examined by the relative location of peaks of fluorescence concentration and OPC zooplankton abundance. Fig. 3 shows that phytoplankton peaks are in areas of low OPC zooplankton abundance, and peaks of fluorescence and zooplankton abundance are nearly $100 \%$ negatively correlated. Thus, we can conclude that the phytoplankton aggregates are very unlikely to contaminate the zooplankton measurements made by the OPC.

The contribution of marine snows to OPC counts was discussed in a series of studies comparing OPC counts with samples from plankton nets (A. W. Herman unpubl.). Results indicated that aggregates were too small for the OPC to measure. Other studies indicated that the marine snows might significantly contribute to the OPC counts (Heath et al. 1999). In our study, because we towed the OPC at a speed of 6 to 7 knots, large marine snow should be broken by the strong turbulent flow in the OPC aperture. The breakup of marine snow has been well studied (Parker et. al. 1972, Tambo \& Hozumi 1979, Tambo \& Watanabe 1979, McCave 1984). Studies indicate that the maximum diameter of an aggregate should be smaller than the Kolmogorove microscale, which can be determined by the shear stress, $\tau$. Aggregates larger than the Kolmogorove microscale will be eroded through the shear stress associated with microscale turbulence. The Kolmogorove microscale is $<100 \mu \mathrm{m}$ at our towing speed of 5 to 6 knots (Tambo \& Watanabe 1979).

\section{Community structure}

The zooplankton community in Sørfjorden, sampled by net tows during the period of investigation, was dominated by Calanus finmarchicus and euphausiids (Figs 4 \& 5). In mid May (Cruise 1) the larvae and furcilia of krill made up the largest portion of the zooplankton, while copepods Oithona spp. and nauplii made up another $10 \%$. Later, in early and mid June (Cruises 2 \& 3), approximately $60 \%$ of zooplankton were $C$. finmarchicus (based on numbers). Though the absolute values of those numbers from net samples are biased by the catch-efficiency of the MOCNESS, it should not affect the percentage values of the speciesstage composition in the same size class.

The overlap between species and stages in a given size range was further investigated by plotting the abundance of a species or stage against its prosome lengths obtained from our laboratory image analysis and literature values (Fig. 5). The prosome lengths for Pseudocalanus minutus and $P$. acuspes were analyzed from samples obtained in the Barents Sea (F. Norrbin unpubl. data), and those for Acartia clausi, Metridia lucens and Oithona spp. were obtained from the literature (Hay et al. 1991). The results showed that the size overlap occurs only between CI of Calanus finmarchicus, adult Pseudocalanus spp. and Acartia spp. Another size overlap occurs between $\mathrm{CV}$ and $\mathrm{Cf}$ of $C$. finmarchicus and the larval stages of euphausiids.

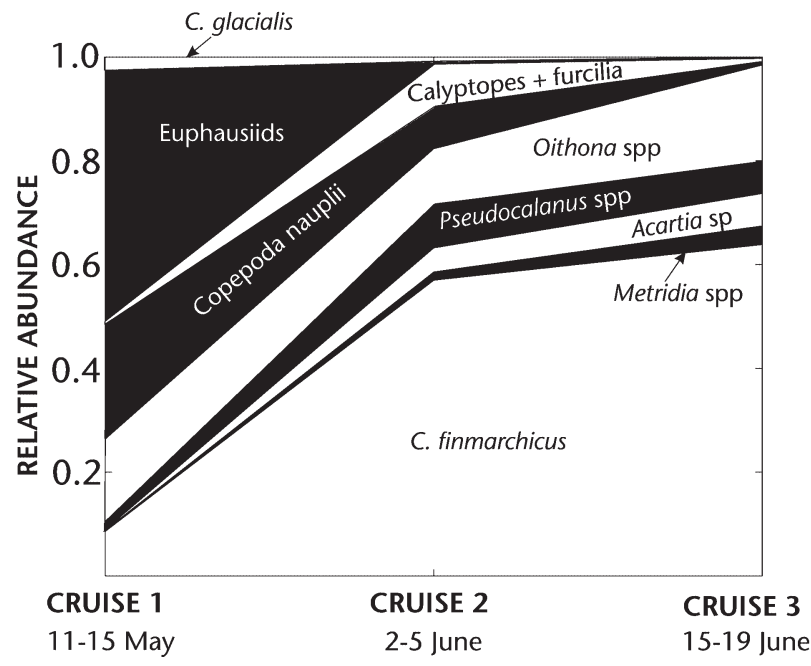

Fig. 4. Community structure of prominent zooplankton species in Sørfjorden given as their relative abundance during the 3 study periods in 1998. Data are obtained from MOCNESS samples and are given as the average from all 3 stations 

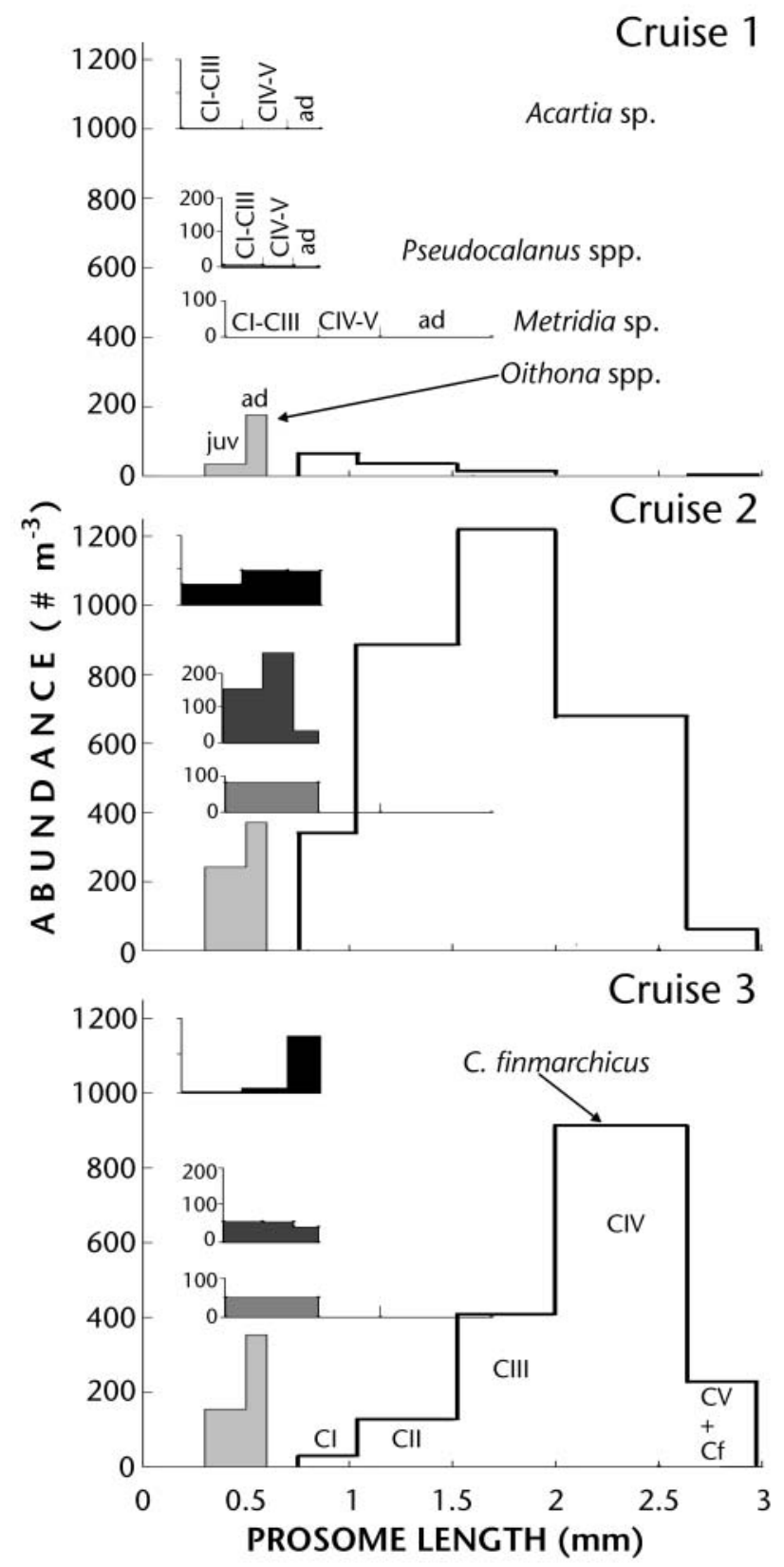

Fig. 5. Abundance of the principal copepod species at different copepodid stages versus their prosome lengths in Sørfjorden. Acartia sp., Pseudocalanus spp., Metridia sp. and Oithona spp. are indicated by shaded areas with baselines shown on the top panel. ad: adult; juv: juvenile. Abundance and prosome length of Calanus finmarchicus CI to CV and adult female are drawn as a non-filled polygon. Note the different scales of abundances

Calyptopes of Thysanoessa longicaudata and T. raschii are within the range of 1.0 to $2.6 \mathrm{~mm}$, and prosome lengths for furcilia vary between 2.7 and $4.0 \mathrm{~mm}$ (Einarsson 1945), which overlaps with CV and adults of C. finmarchicus. Because the relative low abundances of calyptopes and furcilia are $<5,15$ and $2 \%$ of $C$. finmarchicus abundance in Cruises 1 to 3, respectively, C. finmarchicus is the absolutely dominant species in this size range (Fig. 4).

Euphausiids and chaetognaths dominate in the size range larger than Calanus finmarchicus. In Sørfjorden, Thysanoessa inermis, T. raschii, and T. longicaudata were present as 1- (GI) and 2-yr-olds (GII). The ESD of $T$. inermis varies from 2 to $3 \mathrm{~mm}$, and the ESD of Meganyctiphanes norvegica varies from 3 to $6 \mathrm{~mm}$ (Herman et al. 1993). Chaetognaths have a relatively long, transparent body, and a small but dark gut. Where chaetognaths register on the OPC size spectrum is unknown. One- and 2-yr-old individuals of Sagitta elegans have body lengths of 5 to $28 \mathrm{~mm}$, and will likely not interfere with $C$. finmarchicus (Tande 1983).

\section{Non-steady-state biomass spectra}

In previous studies of marine ecosystems, biomass spectra showed a nearly linear decrease from large to small size (Sheldon et al. 1972, Rodriguez \& Mullin 1986). This linearity implies a steady state or a quasisteady state of ecosystems (Zhou \& Huntley 1997). Large fluctuations in biomass and abundance spectra of Loch Linnhe were observed (Heath 1995). However, the annual average of the spectra described a nearly linear relation. The deviation from the straight line is associated with the weight-dependent growth and non-steady state.

The bio-volume spectra from Sørfjorden show curved rather than straight lines, which indicates a non-steady state nature. In theory, the horizontal shift is determined by the individual weight growth, and the vertical shift is determined by the mortality. When combining both weight-dependent growth and mortality, direct interpretation of a single bio-volume spectrum is an impossible task. From the evolution of the spectrum, we can inversely identify the contribution of individual growth or mortality by using Eq. (3) or (11). Because Sørfjorden is dominated by first generation Calanus finmarchicus, the propagation of peak C. finmarchicus from CI to CV takes from 45 to $65 \mathrm{~d}$ depending on temperature (Tande 1988). This propagation of a single generation of $C$. finmarchicus determined the non-steady state nature of the biomass spectra in our survey period.

\section{Individual growth}

Individual growth and mortality rates are calculated based on the theoretical development discussed in the 
Fig. 6. Mean zooplankton growth and mortality rates with $95 \%$ confidence intervals calculated from the bio-volume spectra obtained in Sørfjorden. Arrows indicate the size ranges of some zooplankton groups where $C$ and $E$ are abbreviations for Calanus finmarchicus and Euphausiid, respectively. Thick black bars are population dynamic rates and error ranges from other studies: (1) growth rates estimated from MOCNESS samples in this study; (2) growth rates from Norwegian coastal areas (Marker \& Anderson, unpubl. data); (3) growth rate of euphausiids in the Southern Ocean (Brinton \& Townsend 1991); (4) growth rates of euphausiids in Balsfjorden (Falk-Petersen 1981， 1985); (5) mortality rates of $C$. finmarchicus in a fjord of western Norway (Eiane et al. 1999)

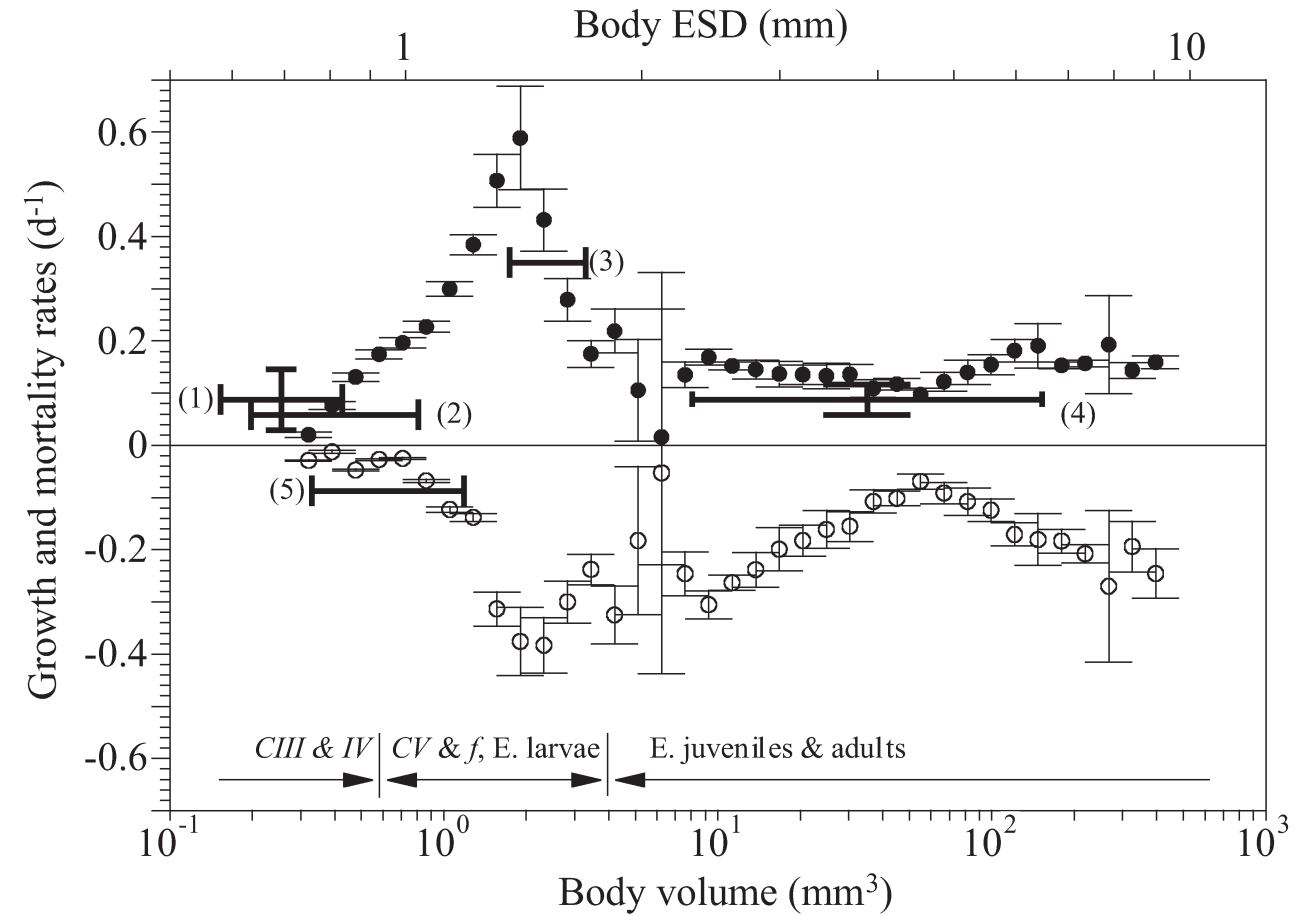

previous section. Results are shown in Fig. 6. The lower limit of sizes for the estimated rates is approximately $w_{m} \approx 0.3 \mathrm{~mm}^{3}$ or the ESD of approximately $0.83 \mathrm{~mm}$ determined by the stability condition of the numerical method Eq. (8). In the size range between 0.3 and $0.58 \mathrm{~mm}^{3}$, the individual growth rate increases from 0.02 to $0.17 \mathrm{~d}^{-1}$. The individual growth rate reaches a distinct peak of $0.59 \mathrm{~d}^{-1}$ at $1.9 \mathrm{~mm}^{3}$ and decreases to $0.22 \mathrm{~d}^{-1}$ at the size of $4 \mathrm{~mm}^{3}$. In the size range between 4 and $40 \mathrm{~mm}^{3}$ the rate decreases from 0.22 to $0.11 \mathrm{~d}^{-1}$, and in the size range above $40 \mathrm{~mm}^{3}$ the rate is in the range 0.1 to $0.2 \mathrm{~d}^{-1}$.

We intend to verify these estimates from net tow samples and literature values. Insufficient numbers of net tow samples, lack of funds for sample sorting and for additional ship time, and necessary quality-control of sampling methods forbid us an independent estimate of the individual growth rate covering the whole OPC size range. Several globally applicable models on copepod growth have been suggested (Ikeda \& Motoda 1975, Huntley \& Lopez 1992, Hirst \& Lampitt 1998). The compiled data on growth rates seem to have a great deal of variance, which may be caused by environmental factors (Kleppel et al. 1996, Hirst \& Sheader 1997). Our estimates, shown in Fig. 6, represent the optimal growth for many size classes of zooplankton in a well-protected fjord environment during a food-rich spring bloom period. Because of restricted environmental conditions, similar studies are rare. The literature values do not cover the whole OPC size range and the resolution. In order to use our estimates from limited net tow samples and literature values, we are obligated to discuss these rates only in 3 size subranges: those dominated by Calanus finmarchicus between 0.3 and $0.58 \mathrm{~mm}^{3}$, by a mixture of C. finmarchicus and euphausiids between 0.58 and $4 \mathrm{~mm}^{3}$, and by euphausiids above $4 \mathrm{~mm}^{3}$.

In the size range between 0.3 and $0.58 \mathrm{~mm}^{3}$ : Based on the analysis of community structure from net tow samples, Calanus finmarchicus are within the range between 0.027 and $1.5 \mathrm{~mm}^{3}$, or 0.5 and $1.8 \mathrm{~mm}$ in ESD (Table 3). C. finmarchicus at CI, CII and CIII are smaller than $w_{m}\left(0.3 \mathrm{~mm}^{3}\right)$, so their growth rates are not estimated. C. finmarchicus at CIV vary between 0.27 and $0.58 \mathrm{~mm}^{3}$ (mean ca $0.4 \mathrm{~mm}^{3}$ ), and they are dominant in this size range. The growth rate in this size range, estimated from the bio-volume spectra, varies from 0.02 to $0.17 \mathrm{~d}^{-1}$.

The abundance estimates from net tow samples are not quantitatively accurate because of clogging and leakage of the mesh, as previously discussed. We have to assume that mortality does not affect the estimate of mean individual size in order to estimate individual growth rate by following mean sizes through different stages. The population of Calanus finmarchicus developed from CI to CIV with a change in mean size from 0.03 to $0.4 \mathrm{~mm}^{3}$. The peaks of CI appeared in Cruise 1, of CIII in Cruise 2, and of CIV in Cruise 3. From previously reported values of stage duration (Hygum et al. 2000a), the time between Cruises 1 and 2, and our MOCNESS samples, we believe that the peak of $C$. finmarchicus recorded during Cruise 1 represented late 
nauplii rather than CI. Since we lack data on bio-volumes of nauplii, CI was used in the calculation. This will lead to underestimation of the growth rate in the period between the first and the second cruise.

The growth rate of CIII to IV (size range 0.13 to $0.58 \mathrm{~mm}^{3}$ ) estimated from net tow samples by Eqs. (18) and (19) has 95\% confidence intervals of 0.01 to $0.15 \mathrm{~d}^{-1}$, and the growth rate estimated from the biovolume spectra (size range 0.3 to $0.58 \mathrm{~mm}^{3}$ ) is 0.02 to $0.17 \mathrm{~d}^{-1}$. Thus, estimates based on net tow samples and bio-volume spectra are statistically indistinguishable.

Growth from CI to $\mathrm{CV}$ represents a change in mass from 5 to $300 \mu \mathrm{g} C$ over a period of approximately $45 \mathrm{~d}$, showing a growth rate of $0.065 \mathrm{~d}^{-1}$ (Marker \& Andreassen unpubl. data). Studies of Calanus finmarchicus in the laboratory (Tande 1988) and Calanus spp. in Raunefjorden, western Norway (Hygum et al. 2000b) showed a similar growth rate. Maximum growth based on Huntley \& Lopez (1992) is approximately equal to $0.05 \mathrm{~d}^{-1}$ at $3^{\circ} \mathrm{C}$. The $95 \%$ confidence intervals of these values are not available. However, these means fall well into the range of 0.01 to $0.15 \mathrm{~d}^{-1}$ by the $95 \%$ confidence interval estimated from net tow samples and the variation of 0.02 to $0.17 \mathrm{~d}^{-1}$ estimated from the biovolume spectra.

In the size range between 0.58 and $4 \mathrm{~mm}^{3}$ : Calanus finmarchicus at $\mathrm{CV}$ and euphausiid calyptopes and furcilia dominate this size range. Growth rates increase from $0.17 \mathrm{~d}^{-1}$ at $0.58 \mathrm{~mm}^{3}$ to a peak of $0.59 \mathrm{~d}^{-1}$ at $1.9 \mathrm{~mm}^{3}$, and then decrease to $0.22 \mathrm{~d}^{-1}$ at $4 \mathrm{~mm}^{3}$. There are no literature values on $\mathrm{CV}$ and adult $C$. finmarchicus to support this peak in individual growth rate. There is limited information about euphausiid larvae (e.g. Falk-Petersen 1985). Most studies have been carried out on juveniles of length ranging from 5 to $10 \mathrm{~mm}$ or greater. One study of euphausiid during the spring bloom in the Southern Ocean indicated that the body length of furcilia could double in $6 \mathrm{~d}$. Estimating from the published values of body length (Brinton \& Townsend 1991) this reflects a linear growth rate of approximately $0.12 \mathrm{~d}^{-1}$. The corresponding rate of change in volume (3 times the linear rate) is approximately $0.36 \mathrm{~d}^{-1}$. This value is reasonably close to our estimate of $0.59 \mathrm{~d}^{-1}$. Why euphausiid larvae have such high growth rates in the spring bloom season is unknown. It could be explained as an evolutionary advantage associated with the relatively short growth season in high latitudes.

In the size range above $4 \mathbf{m m}^{3}$ : Euphausiid juveniles and adults are dominant in this size range. The growth rates estimated from the bio-volume spectra show a decrease from $0.2 \mathrm{~d}^{-1}$ at $4 \mathrm{~mm}^{3}$ to $0.1 \mathrm{~d}^{-1}$ at approximately $40 \mathrm{~mm}^{3}$, and an increase to 0.14 to $0.19 \mathrm{~d}^{-1}$ above $40 \mathrm{~mm}^{3}$. The high growth rate at $4 \mathrm{~mm}^{3}$ may represent the mixture of furcilia and euphausiid juve- niles. The growth rates for juveniles in the size range between 10 and $50 \mathrm{~mm}^{3}$ during the spring bloom were approximately $0.05 \mathrm{~d}^{-1}$ in Balsfjorden (Falk-Petersen 1985). Other data in Balsfjorden show the growth rate varying from 0.04 to $0.1 \mathrm{~d}^{-1}$ for GI of Thysanoessa inermis and T. raschii in the period from April to September (Falk-Petersen 1981, 1985). In the Barents Sea, the growth rates of GI $T$. inermis and $T$. longicaudata are approximately equal to 0.05 and $0.06 \mathrm{~d}^{-1}$, respectively, from March to April (recalculated from Dalpadado \& Skjoldal 1996). At the same latitude in the Southern Ocean, the growth rate of euphausiid juveniles in the size range 8 to $60 \mathrm{~mm}^{3}$ is reported at approximately $0.07 \mathrm{~d}^{-1}$ (Brinton \& Townsend 1991). Though there is a lack of error information on these literature values, our estimated values of growth rates in this size category seem systemically to fall within or slightly above previously reported values from the same area and at the same latitude.

In the size range above $50 \mathrm{~mm}^{3}$, the growth rate for euphausiid adults increases to a maximum of approximately $0.19 \mathrm{~d}^{-1}$ in our estimates from the bio-volume spectra. This value is significantly higher than the estimate of 0.02 obtained in Balsfjorden (Falk-Petersen 1985). We do not have enough information to determine the causes for the disagreement, because of problems during sampling, sorting and data processing. One likely cause may be higher predation on larger individuals from visual predators such as fish. If so, the loss of larger animals due to predation gives an underestimated mean individual size of the population, and in turn, to an underestimated individual growth rate. In our estimates using bio-volume spectra we include both individual growth rates and mortality rates. Our results indicate that the mortality rate is doubled when the size increases from 50 to $400 \mathrm{~mm}^{3}$, which directly supports our assumption of higher predation on larger individuals.

\section{Population mortality}

In the size range between 0.3 and $0.58 \mathrm{~mm}^{3}$, the population growth rate (mortality when negative) varies between -0.03 and $-0.05 \mathrm{~d}^{-1}$. The mortality rate reaches $-0.38 \mathrm{~d}^{-1}$ in the range from 0.71 to $10 \mathrm{~mm}^{3}$. In the size range between 10 and $40 \mathrm{~mm}^{3}$ the rate decreases from -0.31 to $-0.11 \mathrm{~d}^{-1}$, and above $40 \mathrm{~mm}^{3}$ the rate peaks at $-0.27 \mathrm{~d}^{-1}$. Recalculation of these rates from net tow sample data is difficult. The abundance estimates from samples during Cruise 1 are biased by clogging due to abundant phytoplankton aggregates. This problem was significantly reduced during Cruises 2 and 3. The exact effect of clogging on sampling efficiency cannot be quantitatively estimated. 
Table 4. Mortality rate estimated from MOCNESS data. See text and Table 2 for details

\begin{tabular}{|lccccc|}
\hline & \multicolumn{2}{c}{ Cruise I } & \multicolumn{2}{c|}{ Cruise II } & \multicolumn{2}{c|}{ Cruise III } \\
$\begin{array}{llllll}\text { Mean time interval (d) } \\
\text { Dominant stage }\end{array}$ & CI & & CIII & & CIV \\
\hline $\begin{array}{l}\text { Mean abundance } \\
\text { Mortality rates }\left(d^{-1}\right)\end{array}$ & & & 1200 & & 900 \\
& & & & 0.02 & \\
\hline
\end{tabular}

From the limited data, we have the estimate of $-0.02 \mathrm{~d}^{-1}$ only for the size between 0.27 and $0.58 \mathrm{~mm}^{3}$ shown in Table 4, which is comparable to the value estimated from the bio-volume spectra.

Our results show a large variation of mortality from -0.03 to $-0.38 d^{-1}$ in the OPC size range. Similar variation was observed in other studies in other fjords. Eiane et al. (1999) used the population surface method (PSM) to estimate mortality of Calanus spp. in 2 adjacent fjords on the southwest coast of Norway. The stage-specific mortality rate of Calanus spp. in 1 of the fjords was higher for the nauplii $\left(-0.35 \mathrm{~d}^{-1}\right)$ and significantly lower $\left(0.00 \mathrm{~d}^{-1}\right)$ for the early copepodid stages. The stage-specific mortality rate in another fjord showed a fairly constant rate of $-0.08 \mathrm{~d}^{-1}$ for all stages.

\section{Size versus stage structured population dynamics model}

Our results show an application to study population dynamics processes in an ecosystem based on the size structure and an automated instrument. This approach provides estimates of both individual growth and mortality rates at a high size-resolution. If we obtain the information between species-stages and sizes from net tow samples, our estimates as functions of sizes can be easily interpreted by identified species and stages. Hence, there is no gap between models based on size structures and species-stages. The advantages of our approach are: (1) there is no steady-state assumption of the population; (2) there is no need to specify individual growth rates; (3) the automated instrument provides a broader size range of zooplankton at a higher resolution than do traditional methods; and (4) this approach provides more spatial and temporal coverage than traditional net tows.

The biomass spectrum model assumes that a zooplankter body grows continuously rather than discretely. The stage-based model assumes that a zooplankter develops discretely from one stage to the next. The concept of a growth rate generally describes a continuous temporal change of body size, while the duration describes a discrete change between 2 stages. Thus, stage-based models should use discrete mathe- matical equations instead of using continuous mathematical equations. We often use the development rate to describe the continuous change in population between 2 stages; then, the development rate should be determined not only by the stage duration but also by the age structure within the stage (Huntley et al. 1994, Aksnes \& Ohman 1996). It is difficult to determine the age structure within a stage from samples.

A zooplankter grows continuously in body carbon within a stage duration, which a stage-based model ignores. In order to estimate the continuous carbon flow in an ecosystem, the stage-based zooplankton model needs to be improved by inserting a body growth model within a stage (Miller \& Tande 1993). Models based on biomass spectra and stages are then fundamentally similar. The biomass spectrum model uses a much simpler physiological development structure of a zooplankton population and a simpler and more consistent mathematical expression (i.e. Eq. [2]) than does the model integrating discrete stage developments and continuous body growth within a stage.

\section{Summary}

We applied a model based on biomass spectrum to the study of zooplankton population dynamics processes in Sørfjorden, northern Norway. Results show the optimal growth of Calanus finmarchicus and euphausiids in the spring bloom. Especially, the peak growth of euphausiid furcilia in this period, which is observed up to $0.36 \mathrm{~d}^{-1}$ in the Southern Ocean (Brinton \& Townsend 1991), is also observed in our study. Our results are favorably compared to results estimated from our net tow sample and literature values.

The mortality data are rarely obtained in fieldwork, but are important parameters that enclose an ecosystem model. Aksnes \& Ohman (1996) developed a 'vertical life table approach' that was intended to estimate mortality from one measurement of population structure. The vertical method requires estimates of independent stage durations and the assumption of the steady population structure. The strength of our approach is to estimate concurrently both individual growth and population mortality rates of a transient population. This provides a quantitative method to study mortality caused by predation and natural death, and prey-predator interaction.

Our approach is an integration of field measurements and mathematical theories. Net tow samples are among those necessary measurements. Only from the information obtained in net tow samples can we sensibly interpret our estimates as functions of body sizes in terms of species and stages. Compared to stage-based zooplankton models, the biomass spectrum model is 
simpler in both physiological development structure and mathematical expression, in which the only assumption is the continuous growth, without conflicting the discrete stage development and continuous growth within a stage duration.

The mathematical equations in this approach can be applied generally in zooplankton studies. It can be used for studying a population consisting of a single species or multiple species. In this application, we avoided the advection effect by selecting a nearly enclosed fjord. In an advective field, the advection effect can be counted either by using the objective analysis method (Zhou 1998), or by measuring the fluxes of zooplankton across the boundaries of a survey area, which requires further investigation.

Acknowledgements. We thank J. T. Eilertsen and R. Buvang for their technical support, and the crew on RV 'Johan Ruud' for all their help during the cruises. We also thank A. Timonin and T. Semenova for species identification and enumeration. This project was supported by funds from the Norwegian Research Council (project number 121060/122) to K. Tande, and from US NSF Grant OCE-9818569 to M. Zhou and Y. Zhu, who also thank K. Tande for the opportunities to participate in this project.

\section{LITERATURE CITED}

Aksnes DL, Blindheim J (1996) Circulation patterns in the North Atlantic and possible impact on population dynamics of Calanus finmarchicus. Ophelia 44:7-28

Aksnes DL, Magnesen T (1988) A population dynamics approach to the estimation of production of four calanoid copepods in Lindåspollene, western Norway. Mar Ecol Prog Ser 45:57-68

Aksnes DL, Ohman MD (1996) A vertical life table approach to zooplankton mortality estimation. Limnol Oceanogr 41: 1461-1469

Brinton E, Townsend A (1991) Development rates and habitat shifts in the Antarctic neritic euphausiid Euphausia crystallorophias, 1986-87. Deep-Sea Res 38:1195-1211

Brune DE, Anderson TH Jr (1989) Explanation of size diversity among Artemia cohorts: a model of food uptake kinetics. J World Aquacult Soc 20(1):12-17

Carlotti F, Nival P (1991) Individual variability of development in laboratory-reared Temora-Stylifera copepodides - consequences for the population-dynamics and interpretation in the scope of growth and development rules. J Plankton Res 13:801-813

Carlotti F, Nival P (1992a) Model of copepod growth and development: moulting and mortality in relation to physical processes during an individual moult cycle. Mar Ecol Prog Ser 84:219-233

Carlotti F, Nival P (1992b) Moulting and mortality-rates of copepods related to age within: experimental results. Mar Ecol Prog Ser 84:235-243

Dalpadado P, Skjoldal HR (1996) Abundance, maturity and growth of the krill species Thysanoessa inermis and $T$. longicaudata in the Barents Sea. Mar Ecol Prog Ser 144: 175-183

Eiane K (1999) Stage-specific mortality of Calanus spp. under different predation regimes. In: Pelagic food webs: struc- turing effects of different environmental forcing. DSc thesis, University of Bergen

Einarsson H (1945) Euphausiacea I. Northern Atlantic species. Dana-Rep Carlsberg Found 27:1-185

Falk-Petersen S (1981) Ecological investigation of the zooplankton community of Balsfjorden, northern Norway: seasonal changes in body weight and the main biochemical composition of Thysanoessa inermis (Krøyer) and $T$. raschii (M. Sars), and Meganyctiphanes norvegica (M. Sars) in relation to environmental factors. J Exp Mar Biol Ecol 49:103-120

Falk-Petersen S (1985) Growth of the euphausiids Thysanoessa inermis, Thysanoessa raschii, and Meganyctiphanes norvegica in a subarctic fjord, north Norway. Can J Fish Aquat Sci 42(1):14-22

Falk-Petersen S, Hopkins CCE, Rheinheimer G, Fluegel H, Lenz J (1981) Zooplankton sound scattering layers in north Norwegian fjords: interactions between fish and krill shoals in a winter situation in Ullsfjorden and Øksfjorden. In: Zeitschel B (ed) Lower organisms and their role in the food web. Kommissionsverl Walter G. Muehlau, Kiel, Freiburg, p 191-201

Falkenhaug T, Tande K, Timonin A (1997) Spatio-temporal patterns in the copepod community in Malangen, northern Norway. J Plankton Res 19:449-468

Haury LR, McGowan JA, Wiebe PH (1978) Patterns and processes in time-space scales of plankton distributions. In: Steele JH (ed) Spatial patterns in plankton communities. Plenum Press, London, p 277-328

Hay SJ, Kiørboe T, Matthews A (1991) Zooplankton biomass and production in the North Sea during the Autumn Circulation Experiment, October 1987-March 1988. Cont Shelf Res 11:1453-1476

Heath MR (1995) Size spectrum dynamics and the planktonic ecosystem of Loch Linnhe. ICES J Mar Sci 52:627-642

Heath MR, Dunn J, Fraser JG, Hay SJ, Madden H (1999) Field calibration of the Optical Plankton Counter with respect to Calanus finmarchicus. Fish. Oceanogra. 8 (Suppl. 1): 13-24

Herman AW (1988) Simultaneous measurement of zooplankton and light attenuance with a new optical plankton counter. Cont Shelf Res 8:205-221

Herman AW (1992) Design and calibration of a new optical plankton counter capable of sizing small zooplankton. Deep-Sea Res 39:395-415

Herman AW, Cochrane NA, Sameoto DD (1993) Detection and abundance estimation of euphausiids using an optical plankton counter. Mar Ecol Prog Ser 94:165-173

Hirst AG, Lampitt RS (1998) Towards a global model of in situ weight-specific growth in marine planktonic copepods. Mar Biol 132:247-257

Hirst AG, Sheader M (1997) Are in situ weight-specific growth rates body-size independent in marine planktonic copepods? A re-analysis of the global syntheses and a new empirical model. Mar Ecol Prog Ser 154:155-165

Hopkins CCE, Tande KS, Grønvik S, Sargent JR (1984) Biological investigations of the zooplankton community of Balsfjorden, Northern Norway: an analysis of growth and overwintering tactics in relation to niche and environment in Metridia longa (Lubbock), Calanus finmarchicus (Gunnerus), Thysanoessa inermis (Krøyer) and T. rachi (M. Sars). J Exp Mar Biol Ecol 82:77-99

Huntley M (1996) Temperature and copepod production in the sea: a reply. Am Nat 148:407-420

Huntley M, Boyd C (1984) Food-limited growth of marine zooplankton. Am Nat 124:455-478

Huntley ME, Lopez MD (1992) Temperature-dependent pro- 
duction of marine copepods: a global synthesis. Am Nat 140:201-242

Huntley ME, Zhou M, Lopez MD (1994) Calanoides acutus in gerlache strait, Antarctica. 2. Solving an inverse problem in population dynamics. Deep-Sea Res Part II Top Stud Oceanogr 41:209-227

Hygum B, Rey C, Hansen BW (2000a) Growth and development rates of Calanus finmarchicus nauplii during diatom spring bloom. Mar Biol 136(6):1075-1085

Hygum B, Rey C, Hansen BW, Tande K (2000b) Importance of food quality to structural growth rate and neutral lipid reserves accumulated in Calanus finmarchicus. Mar Biol 136(6):1057-1073

Ikeda T, Motoda S (1975) An approach to the estimation of zooplankton production in the Kuroshio and adjacent regions. In: Morton B (ed) Special Symposium on Marine Science. The Pacific Science Assosiation, Hong Kong, p 24-28

Kimmer WJ (1987) The theory of secondary production calculations for continously reproducing populations. Limnol Oceanogr 32:1-13

Kimmer WJ, McKinnnon AD (1987) Growth, mortality, and secondary production of the copepod Acartia tranteri in Western Bay, Australia. Limnol Oceanogr 32:14-28

Kiørboe T, Mohlenberg F, Tiselius P (1988) Propagation of planktonic copepods-production and mortality of eggs. Hydrobiologia 167:219-225

Kiørboe T, Nielsen TG (1994) Regulation of zooplankton biomass and production in a temperate costal ecosystem. 1. Copepods. Limnol Oceanogr 39:493-507

Kleppel GS, Davis CS, Carter K (1996) Temperature and copepod growth in the sea: a comment on the temperature-dependent model of Huntley and Lopez. Am Nat 148: 397-406

Marchuk GI (1975) Methods of numerical mathematics. Springer-Verlag, New York, Heidelberg, Berlin

Massana R, Gasol JM, Bjornsen PK, Blackburn N and 5 others (1997) Measurement of bacterial size via image analysis of epifluorescence preparations: description of an inexpensive system and solutions to some of the most common problems. Sci Mar 61:397-407

McCave IN (1984) Size spectra and aggregation of suspended particles in the deep ocean. Deep-Sea Res 31:329-352

Miller CB, Nielsen RD (1988) Development and growth of large, calanoid copepods in the ocean subarctic pacific May 1984. Prog Oceanogr 20:275-292

Miller CB, Tande KS (1993) Stage duration estimation for Calanus populations, a modelling study. Mar Ecol Prog Ser 102:15-34

Nichols JH, Thompson AB (1991) Mesh selection of copepodite and nauplius stages of four calanoid copepod species. J Plankton Res. 13:661-671

Nisbet RM, Wood SN (1996) Estimation of copepod mortality rates. Ophelia 44:157-169

Ohman MD, Aksnes DL, Runge JA (1996a) The interrelationship of copepod fecundity and mortality. Limnol Oceanogr 41:1470-1477

Ohman MD, Wood SN (1996b) Mortality estimation for planktonic copepods: Pseudocalanus newmani in a temperate fjord. Limnol Oceanogr 41:126-135

Omori M, Ikeda T (1984) Methods in marine zooplankton ecology. John Wiley and Sons, New York

Parker DS, Kaufman WJ, Jenkins D (1972) Floc breakup in turbulent flocculation processes. J Sanit Eng Div Proc Am Soc Civ Eng 98(SA1):79-99

Editorial responsibility: Thomas Kiørboe (Contributing Editor), Charlottenlund, Denmark
Parsons TR, Takahashi M, Hargrave B (1984) Biological oceanographic processes. Pergamon Press, New York

Platt T, Denman K (1977) Organization in the pelagic ecosystem. Helgol Wiss Meeresunters 30:575-581

Platt T, Denman K (1978) The structure of pelagic marine ecosystems. Rapp P-V Réun Cons Int Explor Mer 173: $60-65$

Rodriguez L, Mullin MM (1986) Relation between biomass and body weight of plankton in a steady state oceanic ecosystem. Limnol Oceanogr 31:361-370

Schlichting H (1979) Boundary layer theory. McGraw-Hall, New York

Sheldon RW, TR Parsons (1967) A continuous size spectrum for particulate matter in the sea. J Fish Res Bd Can 24: 909-915

Sheldon RW, Prakash A, Sutcliffe WHJ (1972) The size distribution of particles in the ocean. Limnol Oceanogr 17: $327-340$

Sheldon RW, WH Sutcliffe, MA Paranjape (1977) Structure of the pelagic food chain and the relationship between plankton and fish production. J Fish Res Bd Can 34: $2344-2353$

Sprules,WG, Jin EH, Herman AW, Stockwell JD (1998) Calibration of an optical plankton counter for use in fresh water. J Limnol Oceanogr 43:726-733

Stoer J, Bulirsch R (1980) Introduction to numerical analysis. Springer-Verlag, New York, Heidelberg, Berlin

Tambo N, Hozumi H (1979) Physical characteristics of flocs-II. Strength of floc. Water Res 13:421-427

Tambo N, Watanabe Y (1979) Physical characteristics of flocs-I. The floc density function and aluminum floc. Water Res 13:409-419

Tande KS (1983) Ecological investigation of the zooplankton community of Balsfjorden, northern Norway: population structure and breeding biology of the chaetognath Sagitta elegans Verill. J Exp Mar Biol Ecol 68:13-24

Tande KS (1988) Aspects of developmental and mortalityrates in Calanus finmarchicus related to equiproportional development. Mar Ecol Prog Ser 44:51-58

Tande KS (1991) Calanus in north Norwegian fjords and in the Barents Sea. Polar Res 10:389-407

Tande KS, Slagstad D (1992) Regional and interannual variations in biomass and productivity of the marine copepod, Calanus finmarchicus, in subarctic environments. Oceanol Acta 15:309-321

Wiebe PH, Morton AW, Bradley AM, Backus RH, Craddock JE, Barber V, Cowles TJ, Flierl GR (1985) New developments in the MOCNESS, an apparatus for sampling zooplankton and micronecton. Mar Biol 60:57-61

Wood SN (1994) Obtaining birth and mortality patterns from structured population trajectories. Ecol Monogr 64:23-44

Woodd-Walker RS, Gallienne CP, Robins DB (2000) A test model for optical plankton counter (OPC) coincidence and a comparison of OPC-derived and conventional measurements of plankton abundance. J Plankton Res 22:473-483

Zhang X, Roman M, Sanford A, Adolf H, Lascara C, Burgett R (2000) Can an optical plankton counter produce reasonable estimates of zooplankton abundance and biovolume in water with high detritus? J Plankton Res 22(1):137-150

Zhou M (1998) An objective interpolation method for spatiotemporal distribution of marine plankton. Mar Ecol Prog Ser 174:197-206

Zhou M, Huntley ME (1997) Population dynamics theory of plankton based on biomass spectra. Mar Ecol Prog Ser 159:61-73

Submitted: December 29, 1999; Accepted: May 14, 2001 Proofs received from author(s): February 4, 2002 